\title{
Earth pressure distribution and its impact on retaining pile walls with one level of anchors according to NCh3206 standard
}

Distribución de empujes y su impacto en muros de pilas de entibación con un nivel de anclaje según la norma NCh3206

Fecha de entrega: 2 de febrero 2021 Fecha aceptación: 30 de abril 2021

\section{Dennis Raddatz}

Ferrara - Proyectos Especiales, Av. Ossa 235, oficina 1150, La Reina, Región Metropolitana de Santiago 7870117, Chile, dennis.raddatz@ferrara.cl

In Chile, for the design of an excavation support system, the recommendations of the NCh3206 standard are used, of which its update is being processed. Both for the current standard and for the update, the alternative of uniform or trapezoidal earth pressure distribution for a retaining wall with one anchor level is mentioned. For the current standard, it is indicated that the analysis should be performed for both earth pressure distributions and must be used the most unfavorable for the design of the excavation support system, and for the update it is indicated that one or the other can be used. In this research work, the impact of using one or another earth pressure distribution for projects of discontinuous pile walls is studied. 60 different models are analyzed with characteristic soils from areas with large residential and commercial developments. This means that many retaining projects are developed with these soil conditions for two different types of load after the piles and for five different excavation heights. The difference between what is obtained with both earth pressure distributions is analyzed based on four variables: maximum positive and negative bending moment in the pile, maximum shear in the pile and tension load for the anchor. The results are shown graphically and in tables, in order to appreciate the difference and their magnitude. Finally, comments are delivered, explaining the results obtained.

Keywords: earth pressure, seismic increase, NCh3206, retaining pile walls, anchor
En Chile, para el diseño de entibaciones se usa las recomendaciones de la norma NCh3206, de la cual se está tramitando su actualización. Tanto para la normativa actual, como para la actualización, se menciona la alternativa de distribución del empuje de suelo uniforme o trapezoidal para entibaciones con un nivel de arriostramiento. Para la norma vigente se indica que se debe realizar el análisis para ambas distribuciones de empuje y usar lo que sea más desfavorable para el diseño de los elementos de la entibación, y para la actualización se indica que se puede usar una o la otra. En este trabajo de investigación, se estudia el impacto de usar una u otra distribución para proyectos de pilas discontinuas de entibación, analizándose 60 modelos distintos, con suelos característicos de zonas con gran desarrollo habitacional y comercial. Ello significa que se desarrollan muchos proyectos de entibación con esas condiciones de suelo para dos tipos de carga distintas tras las pilas y para cinco alturas de excavación diferentes. La diferencia entre lo obtenido con una y otra distribución de empuje se analiza en cuatro variables: momento positivo y negativo máximo en la pila, corte máximo en la pila y carga de servicio en el anclaje. Los resultados se muestran gráficamente y en tablas, de manera de poder apreciar las diferencias y la magnitud de estas. Finalmente, se entregan comentarios finales, explicando los resultados obtenidos.

Palabras clave: empuje de suelo, incremento sísmico, NCh3206, pilas de entibación, anclaje

the German EAB (2014) recommendations, the type of earth pressure distribution against the retaining wall varies with the number of anchors levels, their positions, type of retaining wall, stiffness of the wall and the magnitude of the anchor tensioning. According to FHWA (Sabatini et 
al., 1999), the earth pressure distribution that develops in an anchored retaining wall depends on the magnitude and distribution of the deformations that are generated in the wall.

When seismically analyzing a retaining wall model, there is an increase in earth pressure as a result of the increase in the earth pressure coefficient due to the seismic earth pressure. What was originally proposed by Mononobe (1924) and Okabe (1924) is still used, which consists in increasing the coefficient of active earth pressure product of an earthquake. Mononobe-Okabe is a pseudostatic method that is a straightforward extension of the Coulomb sliding wedge theory, incorporating the weight of the wedge multiplied by the acceleration coefficients in the sum of forces of the system (Murthy, 2002). This is equivalent to rotate the earth support system by an angle (turning the screen and emergence of a slope behind the wall with an angle equal to the rotation of the system), the angle of rotation is the angle of the weight resultant vector direction of the system when considering the vertical and horizontal coefficients of seismic acceleration acting on the soil wedge (Towhata, 2008). The seismic increase is the difference between the earth pressure calculated with this coefficient of earth pressure increased by the seismic effect and the earth pressure calculated with the coefficient of active pressure without considering the earthquake effect. The Mononobe-Okabe method has limitations, for example is not valid for walls that are not homogenous along its extension, soils with high cohesion or when phreatic level is acting behind the wall.

Subsequent studies to Mononobe (1924) and Okabe (1924) have recommended the use of this seismic increase in earth pressure acting at a different height than the active earth pressure. For example, Seed and Whitman (1970), based on studies by various authors and related to the location of the resultant force from where the seismic increase force acts, conclude that increase in earth pressure due to the base excitation, are larger near of the top of the wall, then the resultant force increment acts at a height that vary from 0.50 to $0.67 H$, where $H$ is the excavation height of the retaining wall. Using $0.67 H$ is equivalent to using the inverted triangle, as provided by the current Chilean standard for the case of one anchor level (NCh3206, 2010), which is what produces the trapezoidal shape of the resulting earth pressure. It is worth mentioning that there are more recent studies where, on the one hand, it is concluded that during an earthquake there is a phase lag between wall and soil, which affects the magnitude and shape of the thrust, not being triangular, which goes against the Mononobe-Okabe theory (Nakamura, 2006). On the other hand, there are studies where it is concluded that the seismic increase grows monotonically with depth as does the static earth pressure, similar to the original idea of Mononobe and Okabe. For example, there is a study where centrifuge data are analyzed, which consistently show that maximum dynamic earth pressures increase with depth and can be reasonably approximated by a triangular distribution as static earth pressures does (Mikola et al., 2016).

In the current standard in Chile for excavation support systems, it is indicated regarding the earth pressure when there is one anchor level: "When one strut or anchor is projected, for the static case, both a rectangular and triangular earth pressure distribution must be analyzed, using the most unfavorable for the design of strut or anchor and for the wall elements. For the seismic case, an inverted triangular distribution should be used" (NCh3206, 2010). On the other hand, in the proposed modification of the same standard, it is indicated: "When one or more struts or anchors are projected, the kinematics of the excavation support system is not compatible with a triangular distribution of seismic earth pressure. A uniform or trapezoidal type distribution should be considered" (prNCh 3206, 2020). This can be explained because the distribution of the seismic increase pressure is related to the deformation that is allowed along the wall, and it is expected that the deformations near the highest part of the wall will be higher.

Hand-dug piles (rectangular section) or mechanically drilled piles (circular section) are widely used in Santiago for earth retaining projects with advantages and disadvantages of one or the other related to speed, economy, resistance and safety (Raddatz and Taiba, 2017). For purposes of this article the word pile is used to refer to any of both structural elements. This is possible, because variables that define the design of these elements are analyzed, but not the design of the elements itself.

In this work, two forms of earth pressure distribution were analyzed for the seismic condition with one level of anchors 
in the pile system: uniform distribution and trapezoidal distribution. The analysis was made for temporary retaining discontinuous pile wall projects of different excavation heights, for two different surcharge conditions, and in three characteristic soils of Santiago and the coastal zone of Valparaíso. Internal forces in the piles and tension load in anchors are analyzed, specifically the ratio between the variable obtained by trapezoidal distribution and that obtained by uniform distribution is carried out. The results are presented graphically and in order to appreciate the magnitudes of the ratio for each variable, a table is also provided for each graph with the values of each variable. Finally, the conclusions of the results obtained are drawn, in order to be able to realize what it means to use one or another earth pressure distribution.

\section{Methodology}

Due to the low cost and easier installation, using discontinuous piling are very popular in projects with stiff soils and deep groundwater table (e.g. Sáez and Ledezma, 2012; Salas et al., 2019). In this research, geotechnical conditions of this type were considered: three types of soils of the central zone of Chile are used, two from Santiago: Santiago's gravel and pumacita, and dune sand that is found on the coast, specifically in the coastal cities of Viña del Mar and Concón. The chosen soils are very recurrent in projects that require an excavation support system, due to the number of residential and commercial projects that are developed in these types of soils. In addition, soils have a significant variability of strength parameters among them. Table 1 shows the parameters associated with each type of soil.

Table 1: Geotechnical characterization by type of soil used

\begin{tabular}{|c|c|c|c|c|c|c|}
\hline Soil & Stratum ID & $\begin{array}{c}\text { Stratum, } \\
\mathrm{m}\end{array}$ & Description & $\begin{array}{c}\text { Unit weight } \gamma, \\
\mathrm{kN} / \mathrm{m}^{3}\end{array}$ & $\begin{array}{c}\text { Internal friction } \\
\text { angle } \phi,{ }^{\circ}\end{array}$ & Cohesion, $\mathrm{kPa}$ \\
\hline \multirow{2}{*}{$\begin{array}{c}\text { Santiago } \\
\text { gravel }\end{array}$} & $\mathrm{E}-1$ & $0.00-5.50$ & Gravel, second deposit & 22.0 & 45 & 15.0 \\
\cline { 2 - 7 } & $\mathrm{E}-2$ & $>5.50$ & Gravel, first deposit & 23.0 & 45 & 25.0 \\
\hline Pumacita & E-1 & All depth & Silty sand, medium compactness & 15.0 & 35 & 10.0 \\
\hline \multirow{2}{*}{\begin{tabular}{c} 
Dune sand \\
\cline { 2 - 7 }
\end{tabular}} & E-1 & $0.00-4.00$ & Dune sand, medium compactness & 17.5 & 33 & 0.0 \\
\hline
\end{tabular}

The active earth pressure coefficient was calculated following DIN 4085 (1987). The same standard is used to calculate the negative earth pressure produced by cohesion. The analysis was made for two different surcharge conditions behind the retaining wall, on the one hand, considering a four-story building and on the other hand a street condition. Standard NCh3206 (2010) indicates that a surcharge value of $11 \mathrm{kPa}$ must be considered for each floor of a structure adjacent to the retaining wall and a minimum surcharge value of $12 \mathrm{kPa}$ must be considered. In other words, models were made with $44 \mathrm{kPa}$ for the consideration of a four-story structure and other models with $12 \mathrm{kPa}$ for the street condition. For vertical surcharge pressure, a uniform earth pressure with height was considered, equal to the active earth pressure coefficient multiplied by the value of the vertical overload (GGU-Retain, 2012).

According to NCh3206 (2010), the seismic acceleration indicated in the standard NCh433 (2009) must be considered. Specifically, it refers to the effective acceleration, which depends on the seismic zone in which the project is located. The seismic zones divide the country into 3 zones, where higher accelerations are defined from coast to the Andes Mountains. In this case, for the soils of Santiago, the effective acceleration is $0.3 \mathrm{~g}$ associated with zone 2 , and for the coastal zone is $0.4 \mathrm{~g}$ associated with zone 3. In addition, in appendix A of NCh3206 (2010), it is indicated that for the seismic condition a reduction factor $(\alpha)$ can be applied to the effective acceleration indicated above, when considering permanent postseismic displacements at the anchor level $(\Delta \mathrm{eq})$. The value of $\alpha$ depends on the type of soil and the magnitude of the allowed displacement, and additional reduction factors are applied for zones other than zone 3. In the 
proposed prNCh3206 (2020) standard, it is indicated that the maximum allowed displacement $\Delta$ eq to be considered with neighboring structures and with a street are 20 and $40 \mathrm{~mm}$, respectively. In this research, $\Delta$ eq values have been considered within these limits, always allowing less deformation with neighboring structures than with streets. In this way, horizontal seismic coefficients indicated in Table 2 are used depending on the surcharge condition and type of soil, considering that the latter is associated with one or another seismic zone.

Table 2: Seismic acceleration coefficients used

\begin{tabular}{|c|c|c|}
\hline \multirow{2}{*}{ Soil } & Surcharge condition & $\begin{array}{c}\text { Seismic acceleration } \\
\text { coefficient, } g\end{array}$ \\
\hline \multirow{2}{*}{ Santiago gravel } & Street & 0.153 \\
\cline { 2 - 3 } & Four-story building & 0.181 \\
\hline \multirow{2}{*}{ Pumacita } & Street & 0.170 \\
\cline { 2 - 3 } & Four-story building & 0.204 \\
\hline \multirow{2}{*}{ Dune sand } & Street & 0.208 \\
\cline { 2 - 3 } & Four-story building & 0.244 \\
\hline
\end{tabular}

The horizontal seismic coefficient was also used to calculate the horizontal surface-level surcharge, which is obtained by multiplying the horizontal seismic coefficient by the vertical surcharge. For the earth pressure due to horizontal surcharge, a uniform earth pressure with height was considered, where the total horizontal load on the surface in the area of influence to the excavation is distributed throughout the excavation height (GGU-Retain, 2012).

Passive earth pressure is defined as the resistance of a soil mass to lateral pressure displacement (Terzaghi et al., 1996). In the case of retaining walls with one level of anchors, the resistance generated by passive earth pressure in the pile embedded zone is very important, since it is the second support of the system. For the different cases analyzed in this work, variable embedment lengths between 1.5 and $3.5 \mathrm{~m}$ were considered, depending on what is required by the calculation of each model, using a passive earth pressure reduction coefficient of 2.0. The chart of Chadeisson (1961) was used for the evaluation of the horizontal reaction coefficient $k_{\mathrm{h}}$, estimated with values of cohesion and internal friction angle of each type of soil. For the calculation of passive earth pressure, the passive earth pressure coefficient obtained by the Streck method was used (Weissenbach et al., 2003). In this work, two forms of pressure distribution were analyzed for the seismic condition with one level of anchors:

a) Uniform pressure distribution: where all the pressures are added and the total is evenly distributed. The result is a pressure that has a single value over the entire excavation height as shown in Figure 1.



Figure 1: Earth pressure diagrams for uniform distribution

b) Trapezoidal earth pressure distribution: where all the pressures are added without any type of redistribution, and considering the seismic increase pressure as an inverted triangle. The result is a trapezoid, with a top pressure value equal to the maximum pressure per seismic increase plus the surcharge pressures and minus the cohesion pressure, and with a bottom pressure value equal to the maximum active earth pressure plus the pressures per surcharge and minus the cohesion pressure, as shown in Figure 2.

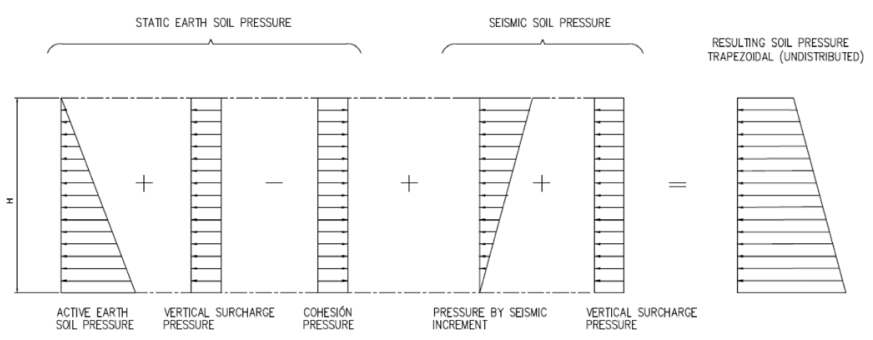

Figure 2: Earth pressure diagrams for trapezoidal distribution

Models with 5 different excavation heights were analyzed $(4,6,8,10$ and $12 \mathrm{~m})$, for the anchoring level, typical anchoring distances to the top pile level were used for each height condition $(1.5,1.8,2.2,2.5$ and $3.0 \mathrm{~m})$. The models were carried out with GGU-Retain (2012), there were 60 models in total with the different alternatives previously described. Figure 3 shows an output of the models developed. GGU-Retain (2012) is a software that allows the analysis of all kind of retaining walls, included discontinuous pile walls. The structural analysis required to 


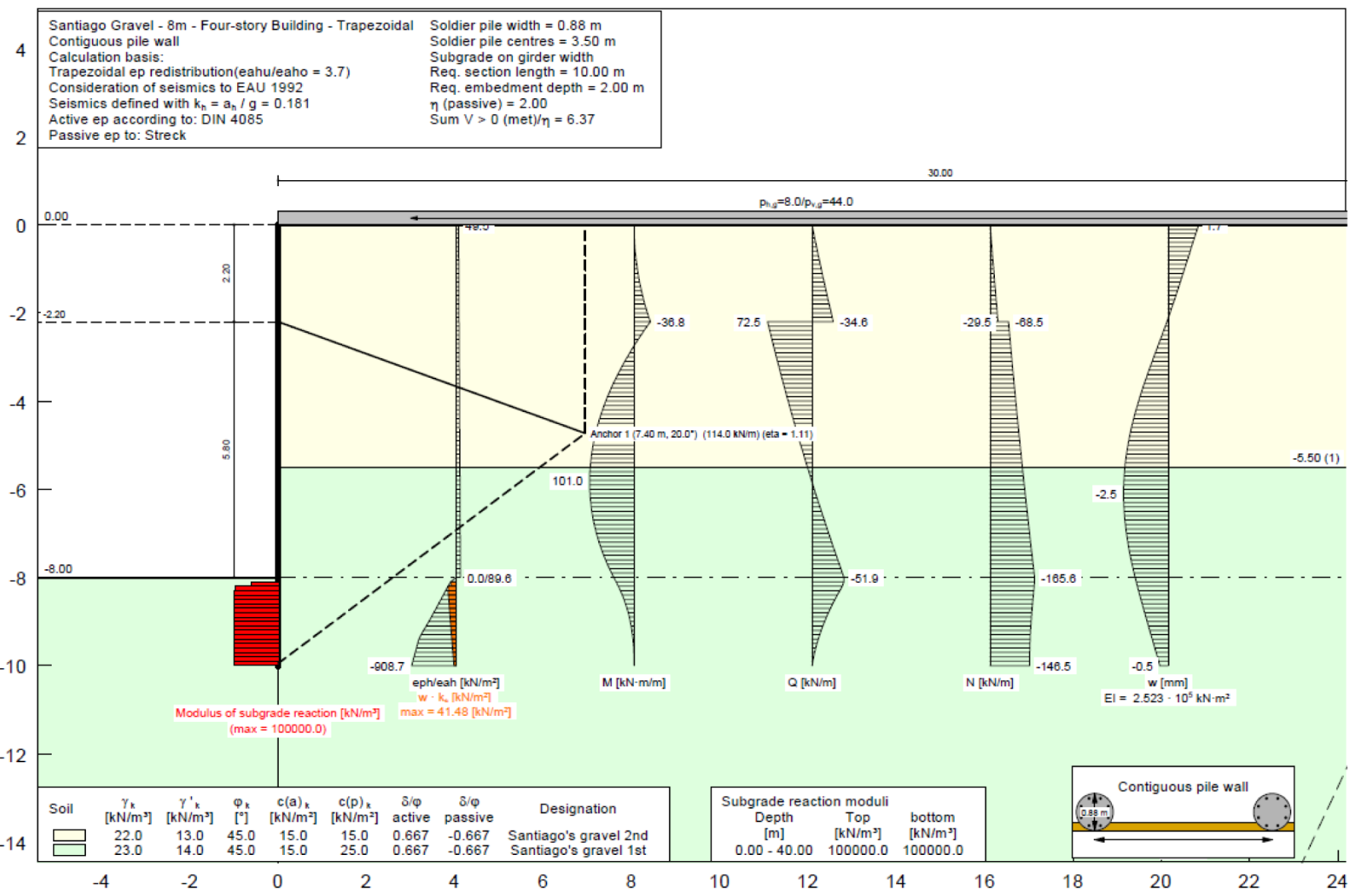

Figure 3: Model output developed with GGU-Retain (2012)

determine the displacement and internal forces (moment, shear force and normal force) is carried out by means of two-dimensional rod construction module based on the finite element method, which treats the retaining wall and any anchor and strut as a single structural system. Elastic analysis at the wall toe with the elastic modulus of subgrade reaction previously defined is performed. Limiting the values of earth pressures to the passive and active value of pressure at that depth. The anchor tension loads and anchor lengths to the middle of the fixed length were obtained employing the stability analysis according to the Kranz wedge, for the most unfavorable case, considering a factor of safety equal to 1.10 for the seismic condition (Kranz, 1953; EAB, 2014; Oróstegui and Villalobos, 2009). The software iterates on the length of each anchor until it reaches the indicated value of 1.10 (GGU-Retain, 2012).

Finally, the ratios between those obtained through a trapezoidal earth pressure distribution and those obtained through a uniform earth pressure distribution of the following variables were analyzed: maximum positive bending moment $(\mathrm{M}+\max )$, maximum negative bending moment (M-max), maximum shear (Vmax) and anchor tension load (Cs). These variables are shown in Figure 4.
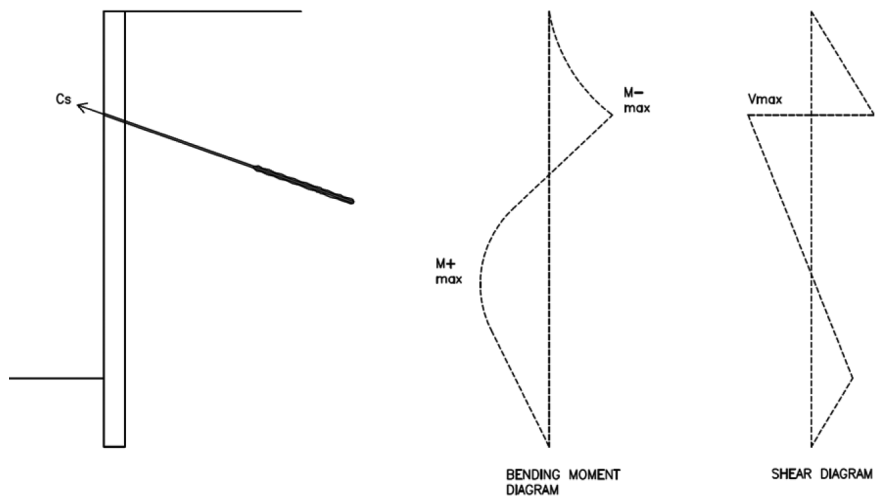

Figure 4: Scheme of pile with analyzed variables

In addition, values of each variables were tabulated, all in units divided per a meter of horizontal excavation, that is, they are independent of the spacing between piles. And to obtain the final values per pile, they should have to be 
multiplied by a typical center pile spacing, which for the cases analyzed in this work are: $3.5 \mathrm{~m}$ in Santiago's gravel, $3.0 \mathrm{~m}$ in pumacita and $2.4 \mathrm{~m}$ in dune sand.

\section{Results}

The ratio values for each variable obtained from trapezoidal earth pressure distribution and rectangular earth pressure distribution are plotted. Six relationship curves are presented per graph, corresponding to the different soil conditions (3 types of soil) and surcharge (2 types of surcharge). In tables that follow each graph, the ratios are expressed as the variable from the trapezoidal distribution over the variable from the rectangular distribution, whose result from the division gives the value indicated in the graph. Results of maximum positive and negative bending moment ratios are shown in Figures 5 and 6 and in Tables 3 and 4, respectively. Results of maximum shear and anchor tension load ratios are shown in Figures 7 and 8 and in Tables 5 and 6, respectively.

It is observed that the largest differences between the results obtained with a trapezoidal earth pressure distribution with respect to those obtained with a uniform earth pressure distribution were obtained for the maximum bending moments, both for the positive moment with the highest value of the ratio of 1.431 , and for the negative moment with a lower value of the ratio of 0.527. All maximum positive moments are higher for the trapezoidal distribution condition, and all maximum negative moments are higher for the uniform redistribution condition.

For the bending moments, it can be seen in the graphs that, for the same surcharge condition, the gravel-like soil curves are the ones that are furthest away from 1.0, while the curves associated with dune sand are the closest to 1.0.

For the case of maximum shear and anchor tension load, the ratio values are closer to 1.0 , that is, there is a smaller difference between the results obtained for both earth

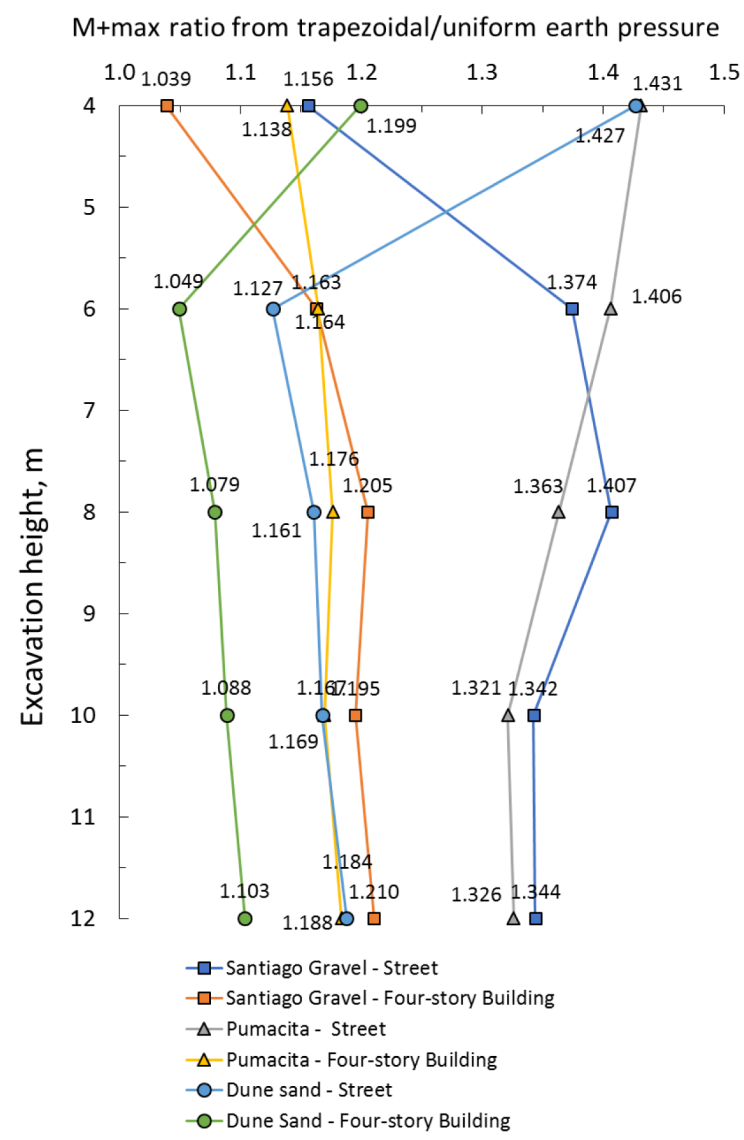

Figure 5: Maximum positive bending moment ratios varying with depth for both earth pressure distributions

pressure distributions. For the bending moment curves, and for the anchor tension load curve, an ordering of the curves by horizontal seismic acceleration coefficient considered in the models is mostly observed. The ordering is ascending or descending depending on the analyzed ratio.

The trapezoidal earth pressure distribution generates differences with respect to the uniform earth pressure distribution, mainly in the bending moments in the piles. In the case of Santiago's gravel with a condition of street behind the piles, the differences in positive bending moment can be up to $43 \%$ higher with the trapezoidal earth

Table 3: Results of maximum positive bending moments with depth for both earth pressure distributions

\begin{tabular}{|l|c|c|c|c|c|}
\hline $\mathrm{M}+\mathrm{max}_{\text {ratio, }} \mathrm{kNmm}^{-1} / \mathrm{kNmm}^{-1}$ & $H=4 \mathrm{~m}$ & $H=6 \mathrm{~m}$ & $H=8 \mathrm{~m}$ & $H=10 \mathrm{~m}$ & $H=12 \mathrm{~m}$ \\
\hline Santiago gravel - street & $3.9 / 3.4$ & $25.7 / 18.7$ & $68.1 / 48.5$ & $147.0 / 109.5$ & $259.0 / 192.7$ \\
\hline Santiago gravel - four-story building & $8.9 / 8.5$ & $42.9 / 36.9$ & $101.0 / 83.8$ & $205.2 / 171.7$ & $344.5 / 284.6$ \\
\hline Pumacita - street & $7.0 / 4.9$ & $36.0 / 25.6$ & $92.3 / 67.7$ & $201.6 / 152.6$ & $355.6 / 268.2$ \\
\hline Pumacita - four-story building & $14.6 / 12.9$ & $64.6 / 55.5$ & $150.2 / 127.7$ & $306.5 / 262.1$ & $510.8 / 431.5$ \\
\hline Dune sand - street & $16.6 / 11.6$ & $56.3 / 50.0$ & $136.5 / 117.6$ & $276.8 / 237.1$ & $460.6 / 387.8$ \\
\hline Dune sand - four-story building & $25.2 / 21.0$ & $88.2 / 84.1$ & $201.9 / 187.2$ & $395.1 / 363.0$ & $634.6 / 575.1$ \\
\hline
\end{tabular}


pressure distribution. Moreover, the differences in negative bending moment can reach up to $47 \%$ higher with uniform earth pressure redistribution. However, the magnitude of the positive bending moment is much higher than that of the negative bending moment, especially in higher piles. This means that in magnitude the bending moment difference is of the same order or higher for the positive bending moment. The most critical condition follows the recommendation of the current standard (NCh3206, 2010), which requires a design for one level of anchored pile with the most unfavorable condition between both earth pressure distributions, which means designing with the uniform distribution for the negative bending moment and the trapezoidal distribution for the positive bending moment. Compared to a design that uses only one type of earth pressure distribution, this may affect the design of the piles in terms of higher steel reinforcement, higher section area, closer piles and/or a second line of anchor.

The differences between the two earth pressure distributions are reduced when the surcharge behind the piles increases. This occurs as the surcharge pressure component grows, and

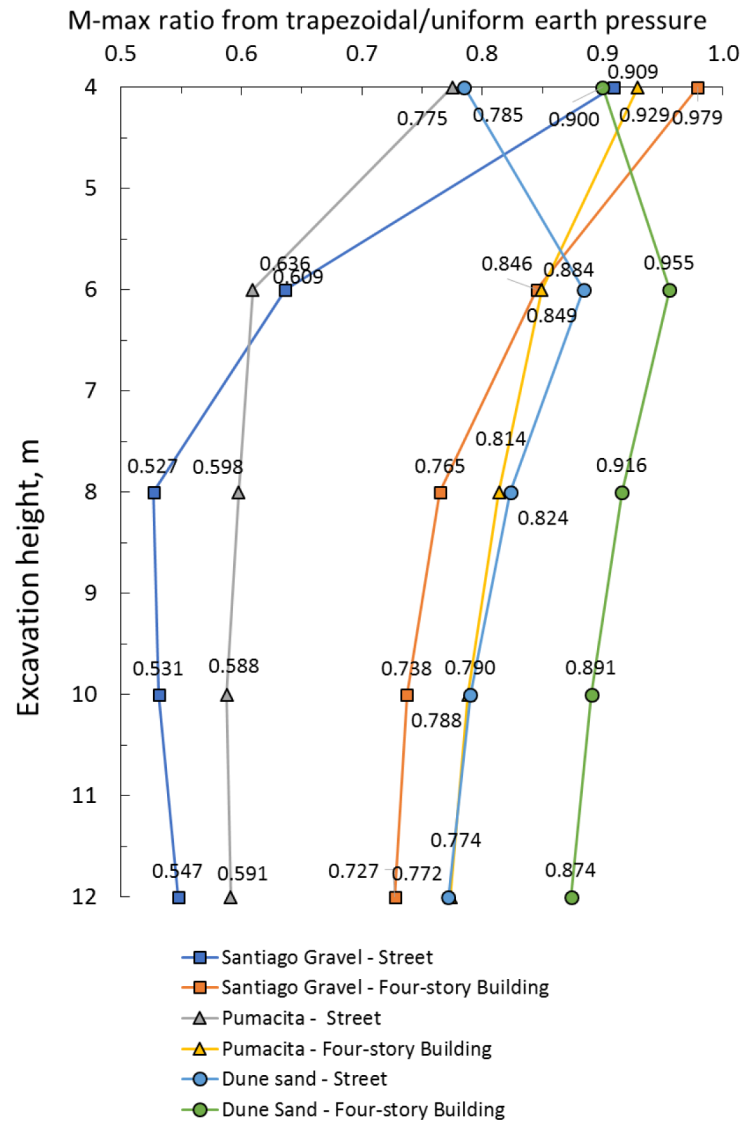

Figure 6: Maximum negative bending moment ratios varying with depth for both earth pressure distributions the seismic component has less weight in the summation of the total pressure. This phenomenon also occurs with higher horizontal seismic acceleration coefficients, since the seismic increase is larger, that is, the upper side of the trapezoid has a greater magnitude. In these cases, it can be said that they cause the trapezoid resulting from the sum of pressures becomes closer to a rectangle. The case of higher surcharge and higher horizontal seismic acceleration coefficient occurs in all the cases of analysis of a four-story building condition versus a street condition, which is the reason of the significant difference between the two analyzes for a same soil condition.

The reduction of the anchor tension load for the trapezoidal earth pressure distribution occurs because a larger portion of the total pressure is mobilized closer to the pile embedment. This means that the second support in the system, which is the embedment, takes a larger pressure component. This was evident since the embedment lengths were controlled in the analysis by the trapezoidal earth pressure distribution condition instead of the uniform distribution.

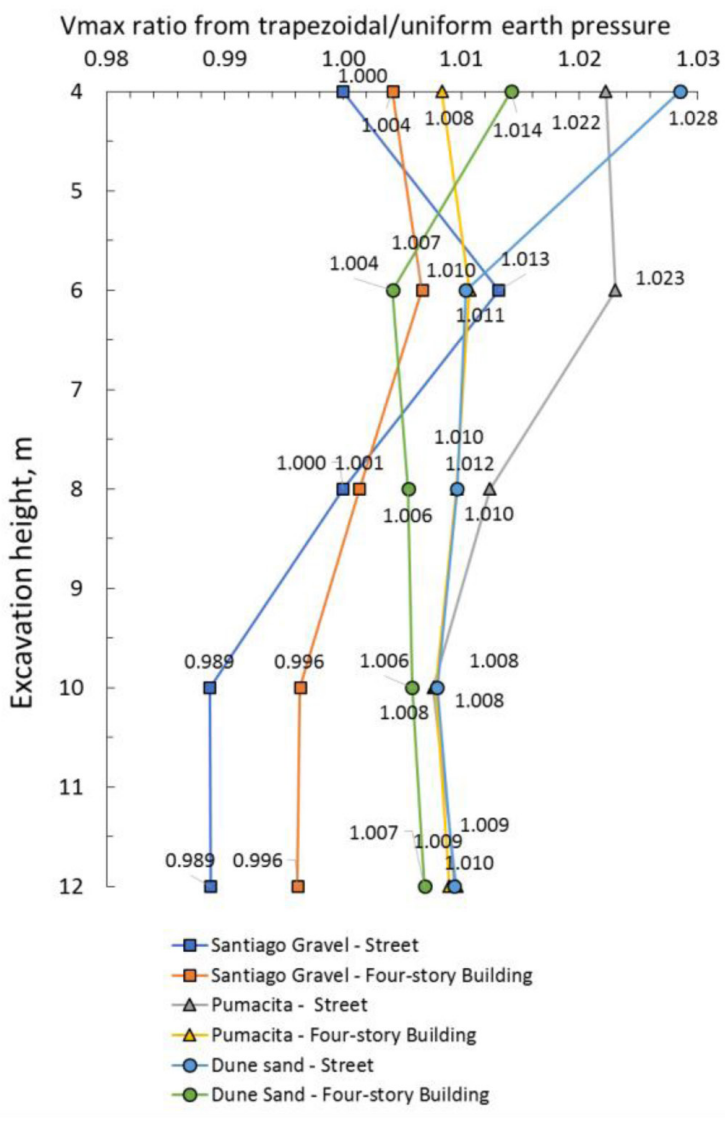

Figure 7: Maximum shear load ratios varying with depth from both earth pressure distributions 
Table 4: Results of maximum negative bending moments with depth for both earth pressure distributions

\begin{tabular}{|l|c|c|c|c|c|}
\hline M-max ratio, $\mathrm{kNmm}^{-1} / \mathrm{kNmm}^{-1}$ & $H=4 \mathrm{~m}$ & $H=6 \mathrm{~m}$ & $H=8 \mathrm{~m}$ & $H=10 \mathrm{~m}$ & $H=12 \mathrm{~m}$ \\
\hline Santiago gravel - street & $5.0 / 5.5$ & $8.4 / 13.2$ & $14.7 / 27.9$ & $26.2 / 49.3$ & $49.7 / 90.8$ \\
\hline Santiago gravel - four-story building & $13.9 / 14.2$ & $21.9 / 25.9$ & $36.8 / 48.1$ & $56.2 / 76.2$ & $95.0 / 130.6$ \\
\hline Pumacita - street & $6.2 / 8.0$ & $10.6 / 17.4$ & $22.0 / 36.8$ & $36.2 / 61.6$ & $64.6 / 109.3$ \\
\hline Pumacita - four-story building & $19.7 / 21.2$ & $31.6 / 37.2$ & $54.7 / 67.2$ & $80.1 / 101.6$ & $130.2 / 168.3$ \\
\hline Dune sand - street & $14.6 / 18.6$ & $29.0 / 32.8$ & $49.0 / 59.5$ & $71.9 / 91.0$ & $117.4 / 152.1$ \\
\hline Dune sand - four-story building & $29.7 / 33.0$ & $51.5 / 53.9$ & $84.0 / 91.7$ & $119.0 / 133.6$ & $187.8 / 214.9$ \\
\hline
\end{tabular}

Table 5: Results of the maximum shear load with depth for both earth pressure distributions

\begin{tabular}{|l|c|c|c|c|c|}
\hline Vmax ratio, $\mathrm{kNm}^{-1} / \mathrm{kNm}^{-1}$ & $H=4 \mathrm{~m}$ & $H=6 \mathrm{~m}$ & $H=8 \mathrm{~m}$ & $H=10 \mathrm{~m}$ & $H=12 \mathrm{~m}$ \\
\hline Santiago gravel - street & $9.4 / 9.4$ & $23.1 / 22.8$ & $42.0 / 42.0$ & $70.0 / 70.8$ & $105.7 / 106.9$ \\
\hline Santiago gravel - four-story building & $24.0 / 23.9$ & $45.2 / 44.9$ & $72.5 / 72.4$ & $109.5 / 109.9$ & $154.6 / 155.2$ \\
\hline Pumacita - street & $13.8 / 13.5$ & $31.1 / 30.4$ & $57.1 / 56.4$ & $92.6 / 91.9$ & $136.7 / 135.4$ \\
\hline Pumacita - four-story building & $36.1 / 35.8$ & $66.0 / 65.3$ & $105.0 / 104.0$ & $155.0 / 153.8$ & $213.7 / 211.8$ \\
\hline Dune sand - street & $32.5 / 31.6$ & $58.5 / 57.9$ & $94.2 / 93.3$ & $139.4 / 138.3$ & $192.9 / 191.1$ \\
\hline Dune sand - four-story building & $57.0 / 56.2$ & $96.2 / 95.8$ & $146.2 / 145.4$ & $207.3 / 206.1$ & $276.6 / 274.7$ \\
\hline
\end{tabular}

The maximum shear does not present a clear tendency of increase or decrease with the trapezoidal redistribution with respect to the uniform one. This occurs because, on the one hand, the sum of positive and negative shear at the anchorage level is lower since the anchor tension load is lower, but on the other hand the positive shear grows with respect to the negative shear, since that the magnitude of pressure is highest between the anchor level and the embedment zone.

In general, it is observed that differences between the results obtained for a trapezoidal and uniform earth pressure distribution are more significant when the excavation height is increased, due to the surcharge component of earth pressure loses weight in the sum of all pressures, since its value is constant with height. Instead, the earth pressure and seismic increment increase in a triangular way with height. Therefore, the higher the excavation is, the total pressure of the trapezoidal distribution will have a more noticeable trapezoid shape (less rectangular). Another tendency was found in the change from 4 to $6 \mathrm{~m}$ height in dune sand, where for $4 \mathrm{~m}$ height there is a more trapezoidal earth pressure distribution shape than with $6 \mathrm{~m}$ height, since it obviously generates larger differences in the variables analyzed with respect to the uniform distribution. This is explained by the fact that this stratigraphic model has a soil horizon with lower values of the resistance geotechnical parameters in the upper $4 \mathrm{~m}$.

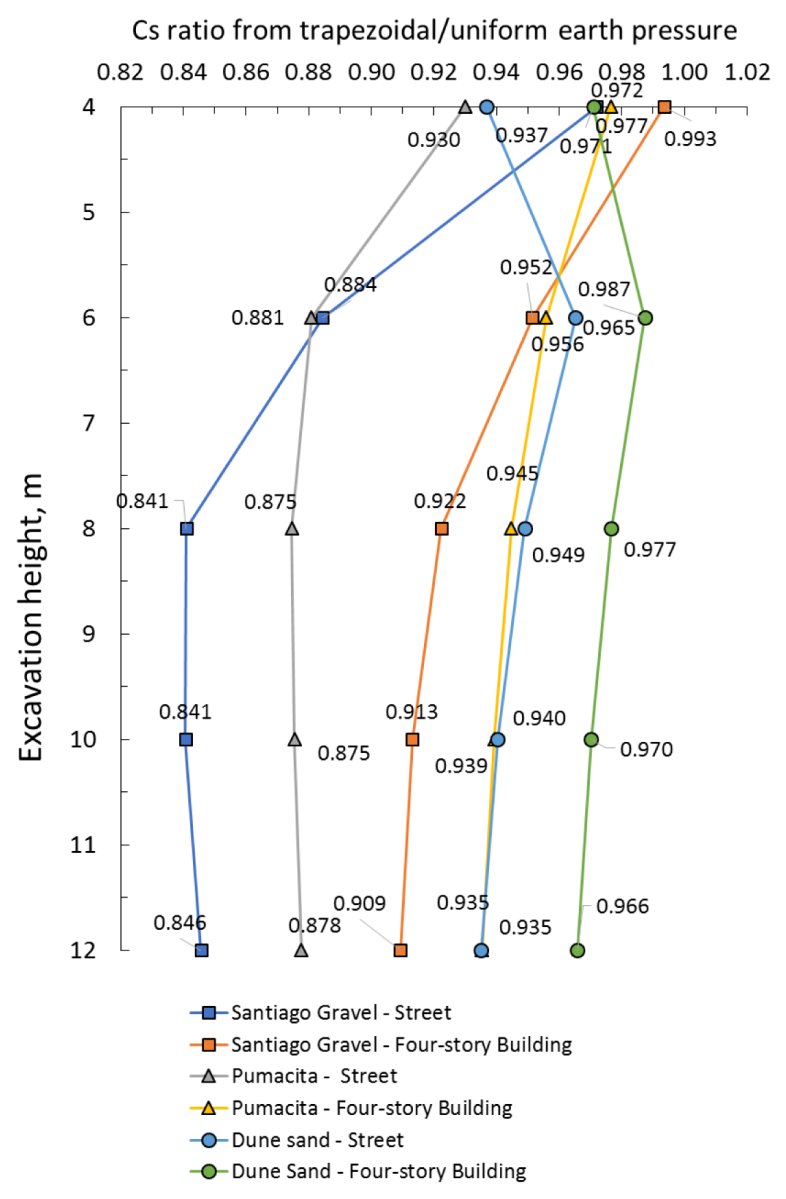

Figure 8: Anchor tension load ratios varying with depth from both earth pressure distributions 
Table 6: Results of anchor tension loads with depth from both earth pressure distributions

\begin{tabular}{|l|c|c|c|c|c|}
\hline Cs ratio, $\mathrm{kNm}^{-1} / \mathrm{kNm}^{-1}$ & $H=4 \mathrm{~m}$ & $H=6 \mathrm{~m}$ & $H=8 \mathrm{~m}$ & $H=10 \mathrm{~m}$ & $H=12 \mathrm{~m}$ \\
\hline Santiago gravel - street & $17.3 / 17.8$ & $35.2 / 39.8$ & $60.3 / 71.7$ & $98.7 / 117.4$ & $150.7 / 178.2$ \\
\hline Santiago gravel - four-story building & $45.3 / 45.6$ & $74.6 / 78.4$ & $114.0 / 123.6$ & $166.0 / 181.8$ & $234.4 / 257.8$ \\
\hline Pumacita - street & $23.9 / 25.7$ & $46.6 / 52.9$ & $83.7 / 95.7$ & $131.5 / 150.2$ & $194.5 / 221.6$ \\
\hline Pumacita - four-story building & $66.6 / 68.2$ & $108.4 / 113.4$ & $166.0 / 175.7$ & $235.0 / 250.2$ & $322.5 / 344.8$ \\
\hline Dune sand - street & $56.3 / 60.1$ & $97.0 / 100.5$ & $148.8 / 156.8$ & $211.2 / 224.6$ & $291.0 / 311.2$ \\
\hline Dune sand - four-story building & $103.5 / 106.6$ & $163.6 / 165.7$ & $237.7 / 243.4$ & $323.1 / 333.0$ & $429.5 / 444.7$ \\
\hline
\end{tabular}

\section{Conclusions}

It was found for the soils and surcharge conditions applied to the anchored piles that the positive bending moment can be up to $43 \%$ higher when using trapezoidal instead of uniform earth pressure distributions in pumacita and dune sand with street surcharge conditions. Conversely, the negative bending moment can be up to $47 \%$ higher when using uniform instead of trapezoidal earth pressure distributions in Santiago gravel and $40 \%$ for pumacita, both with street surcharge conditions. The most critical issue is to follow the recommendation of the current standard NCh3206 (2010), using most unfavorable condition between both earth pressure distributions means designing with the uniform distribution for the negative bending moment and the trapezoidal distribution for the positive bending moment. This results in pile designs with higher steel reinforcement, higher section area, closer piles and/or a second line of anchors in comparison to a design that adopts only one type of earth pressure distribution. For tension load anchors and pile shear, there is a smaller difference between the results obtained for both earth pressure distributions. Moreover, the difference reduces with surcharge increase and with higher horizontal seismic acceleration coefficient. Because it is hard to rely on only one simple earth pressure distribution shape, it is important that the designs of anchored retaining piles consider adequate safety factors that allow for the compensation of uncertainties between the adopted and the real earth pressure distribution.

Regarding pile displacements, all the displacement curves for the final stage analyzed have the shape shown in Figure 3 (right curve), with a maximum negative displacement at the top of the pile and a maximum positive displacement that matches the depth of the maximum positive moment. Both values of displacement are higher for the trapezoidal earth pressure distribution since most of the earth pressure is concentrated in the lower part of the pile, thus generating there a greater positive displacement. On the other hand, less earth pressure in the area of the pile head plus the anchor load towards the ground generates a higher negative displacement. It should be considered that in the previous stage, where there is no anchor, the pile will move towards the excavation, but the displacement curve described for the final stage is the combined effect of tensioning the anchors and increasing the excavation height. Therefore, a displacement analysis must include the effect of all construction stages that impact in the final displacement curve.

\section{References}

Chadeisson, R. (1961). Parois continues moulées dans le sol. 5th European Conference on Soil Mechanics and Foundation Engineering. Dunod, Paris, France, vol. 2, 563-568

DIN 4085 (1987). Subsoil - Calculation of earth-pressure. Berlin, Germany

EAB (2014). Recommendations on excavations. German Geotechnical Society DGGT, Ernst \& Sohn, Berlin, Germany

GGU-Retain (2012). Manual version 7. Civilserve Gmbh, Steinfeld, Germany

Kranz, E. (1953). Über die verankerung von Spundwänden. Ernst \& Sohn, Berlin, Germany

Mikola, R.G., Candia, G. and Sitar, N. (2016). Seismic earth pressures on retaining structures and basement walls in cohesionless soils. Journal of Geotechnical and Geoenvironmental Engineering 142(10), 04016047

Mononobe, N. (1924). Considerations into earthquake vibrations and vibration theories. Journal of the Japanese Society of Civil Engineers 10(5), 1063-1094 (in Japanese) 
Nakamura, S. (2006). Reexamination of Mononobe-Okabe theory of gravity retaining walls using centrifuge model tests. Soils and Foundations 46(2), 135-146

Murthy, V. N. S. (2002). Geotechnical engineering, principles and practices of soil mechanics and foundation. Marcel Dekker, Inc. New York, USA

NCh3206 (2010). Geotecnia - excavaciones, entibaciones y socalzados - requisitos. Instituto Nacional de Normalización INN, Santiago, Chile

prNCh3206 (2020). Geotecnia - excavaciones, entibaciones y socalzados - requisitos. Instituto Nacional de Normalización INN, Santiago, Chile

NCh433 (2009). Diseño sísmico de edificios. Instituto Nacional de Normalización INN, Santiago, Chile

Okabe, S. (1924). General theory of earth pressure and seismic stability of retaining wall and dam. Journal of the Japanese Society of Civil Engineers 10(5), 1277-1323

Oróstegui, P. y Villalobos, F. (2009). Diseño y construcción de entibaciones para los estacionamientos subterráneos de los Tribunales de Justicia de Concepción. Obras y Proyectos 6, 63-71

Raddatz, D. and Taiba, O. (2017). Anchored piles in Santiago's gravel: modeling results for displacement curve. Revista de la Construcción 16(3), 457-467
Sabatini, P.J., Pass, D.G. and Bachus R.C. (1999). Geotechnical engineering circular No. 4: Ground anchors and anchored systems. Federal Highway Administration, FHWA A-IF-99-015, Washington DC, USA

Sáez, E. and Ledezma, C. (2012). Earthquake-induced pressures on discontinuous piling support on Santiago gravel. Soil Dynamics and Earthquake Engineering 41, 72-83

Salas, F., Sáez, E., Ovalle, C. y Fernández, J.M. (2019). Análisis dinámico de una excavación profunda contenida mediante pilotes anclados en la grava de Santiago. Obras y Proyectos 25, $76-82$

Seed, H.B. and Whitman, R.V. (1970). Design of earth retaining structures for dynamic loads. ASCE Specialty Conference on Lateral Stresses in the Ground and Design of Earth-Retaining Structures, Ithaca, USA, 103-147

Terzaghi, K., Peck, R.B. and Mesri, G. (1996). Soil mechanics in engineering practice. John Wiley \& Sons, New York, USA

Towhata, I. (2008). Geotechnical earthquake engineering. Springer, Berlin, Germany

Weissenbach, A., Hettler, A. and Simpson, B. (2003). Stability of excavations. Geotechnical Engineering Handbook: Elements and Structures. U. Smoltczyk (ed.), Ernst \& Sohn, Berlin, Germany, vol. 3, 273-407 